\title{
Adhesion in vitro of Oral Streptococci to Porcelain, Composite Resin Cement and Human Enamel
}

\author{
Tomomasa TAKATSUKA, Norifumi KONISHI, Satoshi NAKABO, \\ Takeshi HASHIMOTO, Yasuhiro TORII and Masahiro YOSHIYAMA \\ Department of Operative Dentistry, Okayama University Dental School, \\ 2-5-1 Shikata-cho Okayama 700-8525, Japan
}

Received July 14, 2000/Accepted September 22, 2000

\begin{abstract}
We investigated the initial adhesion in vitro of oral streptococci to porcelain inlays. Four strains of streptococci, Streptococcus mitis NCTC12261, Streptococcus oralis ATCC9811, Streptococcus sanguis ATCC10556 and Streptococcus sobrinus OMZ176, were used in this study. The disc specimens were made of porcelain, composite resin cement and human enamel. These specimens, with or without a saliva-coat, were immersed in a suspension of each streptococci strain at $37^{\circ} \mathrm{C}$ for $1 \mathrm{hr}$, and the numbers of cells adhering to specimens were counted after staining. The saliva-coat significantly decreased the numbers of adhering cells in all strains tested $(t$-test, $\mathrm{p}<0.05)$. The adhesion to the porcelain and resin cements could be explained by a thermodynamic approach, although the adhesion to enamel could not be explained. These results indicated the possibility that the mechanism is different in initial adhered strains of streptococci between enamel and dental restorative materials.
\end{abstract}

Key words : Bacterial adhesion, Oral streptococci, Porcelain inlay

\section{INTRODUCTION}

Secondary caries is still one of the major causes of replacement of restorations ${ }^{1-3)}$, although remarkable progress has been made in the technology for developing restorative materials and procedures in recent years. It is obvious that the bacterial accumulation at the interface between the restorative materials and the teeth is a key factor for inducing secondary caries around restorations. In the process of plaque formation on solid surfaces such as teeth or restorative materials, initial adhesion of the colonizing bacteria on the surface is very important. After the formation of a bacterial layer initiated by the adhesion of "early colonizers", other bacteria accumulate over the layer so that a thick dental plaque is created. This dental plaque can work as a reservoir of acid produced by cariogenic bacteria and thus secondary caries may be induced.

It is reported that oral streptococci, particularly Streptococcus mitis, Streptococcus oralis and Streptococcus sanguis, are dominant in early bacterial communities on the surface ${ }^{4,5)}$. On the other hand, the cariogenicity of Streptococcus mutans and Streptococcus sobrinus are well known ${ }^{6}$. Therefore, the mechanism of initial adhesion to teeth or restorative material surfaces has been investigated in many in vitro studies, using these strains of streptococci ${ }^{7)}$. These studies demonstrated that the initial bacterial adhesion is closely related to the physicochemical properties of the 
materials. However, the initial bacterial adhesion at the restoration-tooth interface may be more complicated, because restoration-tooth interface is composed of two or more materials. For example, it is necessary to consider the physicochemical properties of three different materials, inlay, cement and tooth enamel, when considering the initial bacterial adhesion at the inlay-tooth interface. Although the bacterial adhesion at the restoration-tooth interface may be very important for secondary caries formation, there is little information on the mechanism of initial bacterial adhesion at the restoration-tooth interface.

Recently, due to increased demand for esthetic treatment even in posterior restoration, much attention has been paid to tooth-colored inlay restoration. Among many esthetic inlay restorations, porcelain inlay restoration is useful because it is highly esthetic and has better biocompatibility. However, little is known about the microbiological aspects concerning the mechanism of secondary caries formation around porcelain inlay restoration, although the physicochemical properties of porcelain, resin cement and enamel, which are used in the restoration, may be greatly different.

The purpose of this study was to investigate the initial streptococcal adhesion in vitro to porcelain, resin cement and enamel in order to better understand the mechanism of bacteria accumulation causing secondary caries formation.

\section{MATERIALS AND METHODS}

\section{Preparation of specimens}

A composite resin cement (Scotch bond resin cement, 3M, USA), porcelain block (Cerec2 Vitablocs Mark II, Vita, Germany) and extracted human incisor enamel were used in this study (Table 1). For the resin cement specimen, the mixed cement was poured into a plastic splitting mold with a diameter of $10 \mathrm{~mm}$ and thickness of $2 \mathrm{~mm}$. Both sides of the splitting mold were clamped with slide glasses and cured using a light-curing unit (Visilux2, 3M Co., St. Paul, MN) from both sides for $80 \mathrm{sec}$ each. For the specimens of human enamel and porcelain blocks, disks with a diameter of $10 \mathrm{~mm}$ and thickness of $2 \mathrm{~mm}$ were cut using a diamond point attached to an air turbine handpiece with a water coolant. The surfaces of specimens were ground with 2000-grid silicon carbide paper under wet conditions and polished with a polishing solution containing $0.05 \mu \mathrm{m}$ aluminum oxide powder. Care was taken to maintain the surface roughness of each specimen at a constant level. Four specimens of each

Table 1 Materials used in this study

\begin{tabular}{lll}
\hline \multicolumn{1}{c}{ Materials } & \multicolumn{1}{c}{ Products } & \multicolumn{1}{c}{ Manufacturers } \\
\hline Resin cement & Scotch Bond Resin Cement & 3M Dental Products, \\
& & MN, USA \\
Porcelain & Cerec2 Vitablocs Mark II & $\begin{array}{l}\text { Vita Zahnfabnk, } \\
\text { Bad Sackingen, Germany }\end{array}$ \\
\hline
\end{tabular}


material were prepared and stored in water at $37^{\circ} \mathrm{C}$ for $24 \mathrm{hr}$.

\section{Saliva-coating of specimens}

Whole unstimulated saliva was collected in chilled tubes and filtrated with a cellulose acetate filter with pore diameter of $0.45 \mu \mathrm{m}$ (DISMIC-25CS, Toyo Roshi Kaisya, Ltd., Tokyo, Japan) to remove debris and bacteria. The saliva was frozen at $-4^{\circ} \mathrm{C}$ before use. Two specimens of each material were immersed in whole saliva for 60 min at $37^{\circ} \mathrm{C}$, then washed in distilled water and immediately used for characterization and adhesion tests.

\section{Bacterial strains and culture conditions}

Streptococcus mitis NTCC12261, Streptococcus oralis ATCC 9811, Streptococcus sanguis ATCC 10556 and Streptococcus sobrinus OMZ 176 were used. All cells were grown in a brain heart infusion broth (Difco Laboratories, Detroit, MI, USA) supplemented with $0.5 \%$ yeast extract. The cells were harvested during the exponential growth phase by centrifugation at $4^{\circ} \mathrm{C}$ for $15 \mathrm{~min}$. After the cells were washed twice with $10 \mathrm{~mol} / \mathrm{L}$ Tris HCI buffer (pH7.2), bacteria were suspended in the buffer. The optical density of the suspension was adjusted to 0.3 at $600 \mathrm{~nm}$.

\section{Adhesion test}

The specimens with or without a saliva-coating were placed inside a beaker with a double-sided adhesive tape, forming a circle around the central area, which was occupied by a magnetic stirring rod. Bacterial suspensions were poured into the beaker and the suspension was stirred at a constant speed for $1 \mathrm{hr}$. at $37^{\circ} \mathrm{C}$. After each test period, each specimen was removed, washed with distilled water, fixed with $2.5 \%$ glutaraldehyde solution at $4^{\circ} \mathrm{C}$ for $30 \mathrm{~min}$, and stained with $1 \%$ crystal violet solution for $30 \mathrm{sec}$. The number of adhered bacterial cells was determined by counting them directly under a microscope. The number of bacteria in each of 20 fields selected at random on each specimen was counted and the number of cells per $\mathrm{mm}^{2}$ was also calculated. The data were statistically analyzed using Student's $t$-test at a significance level of 0.05 .

Measurement of the contact angle and determination of the surface free energy (SFE) of materials and bacterial cells

The contact angle was measured as the index of hydrophobicity of materials with or without a saliva-coat, and oral streptococci bacterial cells were tested. Ten specimens were measured. In order to measure the contact angle of streptococci, they were incubated in a brain heart infusion broth for $24 \mathrm{hr}$, and washed with $10 \mathrm{ml}$ of a phosphate buffer solution. Bacterial cells were collected on a cellulose triacetate filter with a pore diameter of $0.45 \mu \mathrm{m}$ (DISMIC-25CS, Toyo Roshi Kaisya, Ltd.) and dried for $1 \mathrm{hr}$. Then, the contact angle was measured when $5 \mu \mathrm{L}$ of $100 \mathrm{mM} \mathrm{NaCl}$ and $\alpha$-bromonaphthalene were gently dropped on each specimen. Subsequently, the surface free energy (SFE) and the polar and the non-polar components were calcu- 
lated from the contact angle data of the two liquids using a geometric mean equation $^{8)}$.

Determination of interfacial free energy ( $\Delta$ Gadh)

The change in the interfacial free energy $(\Delta G a d h)$ when the bacteria adhered to a
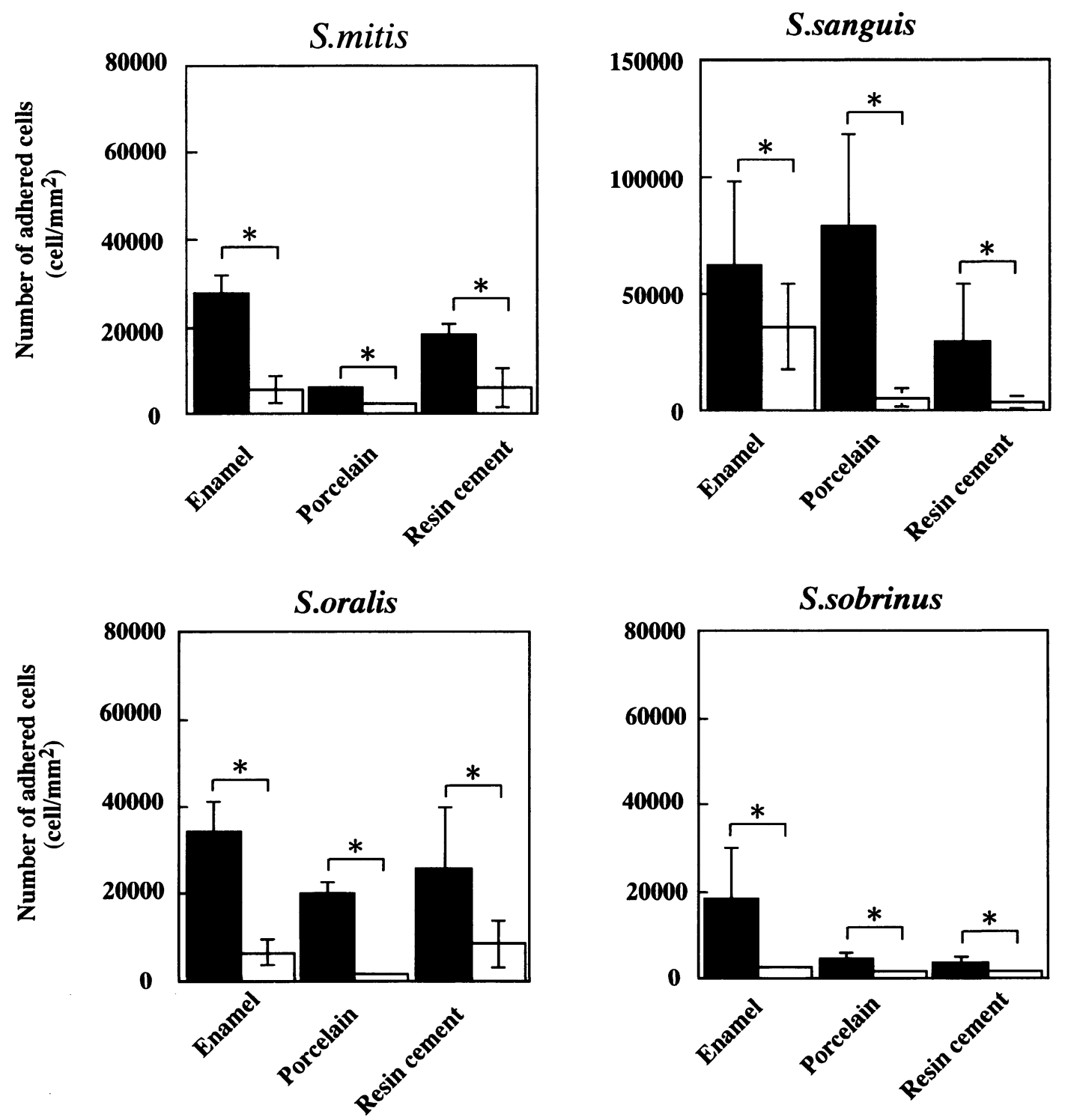

Fig. 1 Numbers of streptococcal cells adhering to uncoated and saliva-coated porcelain, resin composite luting cement and enamel.

Black squares: Without saliva-coat, White squares: With saliva-coat.

Brackets indicate statistically significant differences. $(P<0.05)$ 
solid surface was calculated using the following equation:

$\Delta G a d h=\gamma_{\mathrm{BS}}-\gamma_{\mathrm{BL}}-\gamma_{\mathrm{SL}}$

Here, $\gamma_{\mathrm{BS}}$ is the bacterium-solid interfacial free energy, $\gamma_{\mathrm{BL}}$ is the bacterium-liquid interfacial free energy and $\gamma_{\mathrm{SL}}$ is the solid-liquid interfacial free energy. According to the SFE of the specimen, bacteria and liquid (buffer), the interfacial free energy between the bacterial surface and solid surface can be calculated ${ }^{9)}$.

\section{RESULTS}

Adhesion of streptococcal cells to specimens with and without a saliva-coat

Fig. 1 shows the number of streptococcal cells adherent to porcelain, resin cement and enamel with and without a saliva-coat. When comparing among the specimens without saliva-coat, enamel showed the highest adhesion of S. mitis NCTC12261, S. oralis ATCC9811 and S. sobrinus OMZ176 and the resin cement showed the lowest adhesion. Intermediate amounts were observed in their adhesion to porcelain.

On the other hand, S. sanguis ATCC10556 presented the highest adhesion to resin cement and the number of these cells adhering to porcelain was lower than that to enamel.

Treatment with a saliva-coat reduced the number of bacterial cells adhering to all materials. However, adhesion of S. sanguis ATCC10556 to enamel was not greatly affected by the saliva-coat, but that to porcelain and resin cement was strongly affected.

Regardless of having a saliva-coat or not, S. sobrinus OMZ176 presented the lowest adhesion to all materials, while S. sanguis ATCC10556 presented the highest adhesion to all materials except the porcelain and enamel with saliva-coating.

Table 2 Surface free energy of the materials

\begin{tabular}{lc}
\hline \multicolumn{1}{c}{ Materials } & Surface free energy $\left(\mathrm{mJ} / \mathrm{m}^{2}\right)$ \\
\hline Enamel & 66.7 \\
Porcelain & 42.5 \\
Resin cement & 38.4 \\
Enamel (saliva-coat) & 54.6 \\
Porcelain (saliva-coat) & 53.0 \\
Resin cement (saliva-coat) & 55.8 \\
\hline
\end{tabular}

Table 3 Surface free energy of the bacteria

\begin{tabular}{lc}
\hline \multicolumn{1}{c}{ Bacteria } & Surface free energy $\left(\mathrm{mJ} / \mathrm{m}^{2}\right)$ \\
\hline S.mitis NTCC12261 & 44.2 \\
S.oralis ATCC9811 & 47.2 \\
S.sanguis ATCC10556 & 49.8 \\
S.sobrinus OMZ176 & 63.4 \\
\hline
\end{tabular}




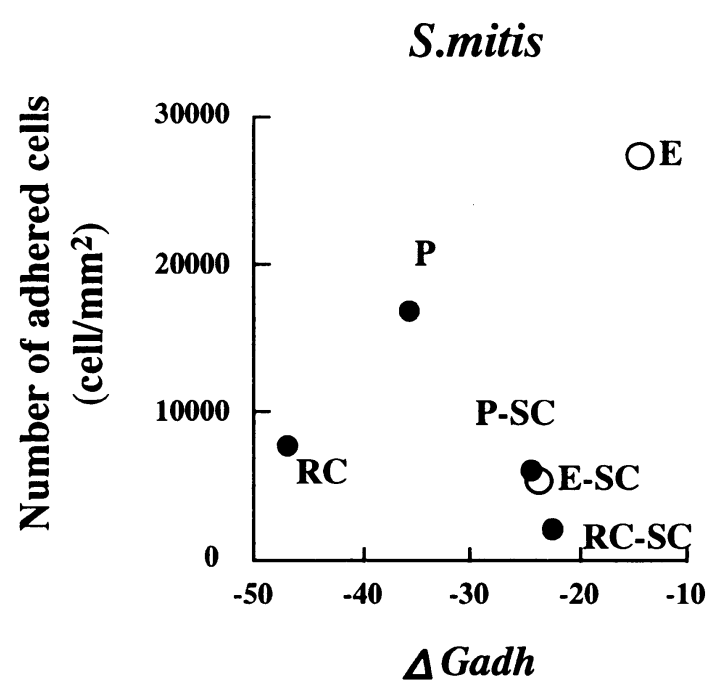

S.oralis

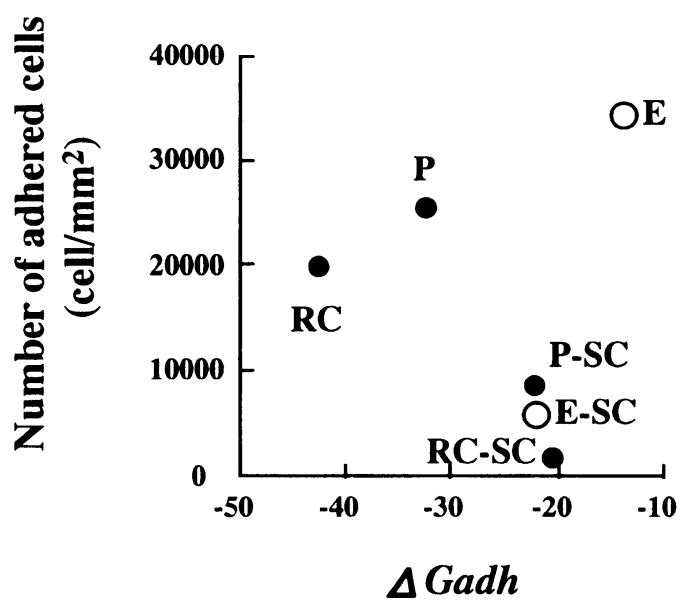

S.sanguis

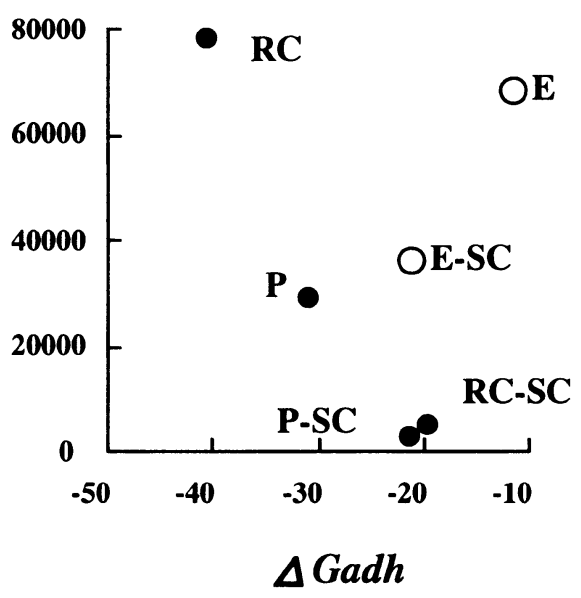

S.sobrinus

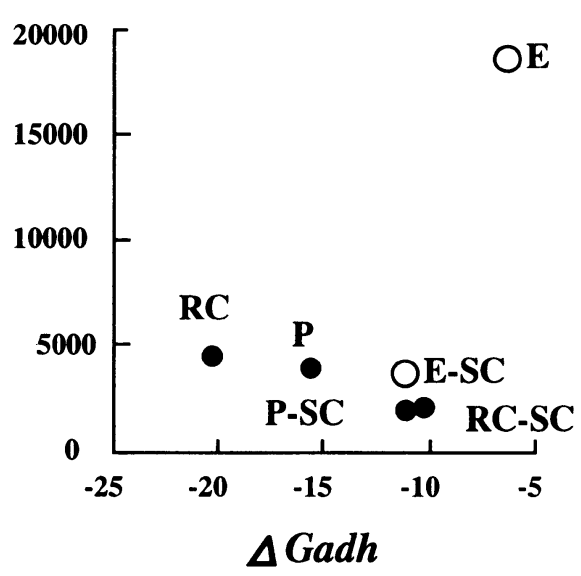

Fig. 2 Relationship between $\Delta$ Gadh and number of adhered cells.

E: Enamel, P: Porcelain, RC: Resin cement, E-SC: Enamel with saliva-coat, P-SC: Porcelain with saliva-coat, RC-SC: Resin cement with saliva-coat.

Surface characteristics of the materials and streptococci

The SFE of the materials and bacteria are shown in Tables 2 and 3, respectively. When SFE values were compared among materials, the enamel surface without a saliva-coat had the highest $\operatorname{SFE}\left(66.7 \mathrm{~mJ} / \mathrm{m}^{2}\right)$, while resin cement showed the lowest $\left(38.4 \mathrm{~mJ} / \mathrm{m}^{2}\right)$, but was relatively close to the value of porcelain. Treatment with a saliva-coat decreased the SFE of enamel slightly, but greatly increased the SFEs of porcelain and resin cement, thus changing the SFEs of the three materials with a 
saliva-coat to almost the same value. When comparing SFE values of bacteria, $S$. sobrinus OMZ176 had the highest value, but the other three strains had almost the same values.

\section{Relationship between $\Delta$ Gadh and number of adhered bacterial cells}

Fig. 2. shows the relationship between $\Delta G a d h$ and the number of adhered streptococci. The cells adhering cells to all materials, except for enamel without a salivacoat, tended to reduce in number with increasing $\Delta$ Gadh value.

\section{DISCUSSION}

In restorative dentistry, a majorproblem is secondary caries occuring around the margins of restorative materials. In the case of porcelain inlay restoration, the bacteria accumulating on the margins may play an important role in the formation and development of secondary caries, since theybegin at the marginal enamel. The initial bacterial adhesion to a solid surface is related to its physicochemical properties ${ }^{10)}$. Since the margin in porcelain inlay restoration consists of three materials, porcelain, resin cement and enamel, differences in physicochemical properties among the three materials may make bacterial accumulation on the margin complicated. To obtain more information on bacterial accumulation on the margins of porcelain inlay restoration, the initial adhesion of oral streptococci to the surfaces of porcelain, enamel and resin cement was investigated and physicochemically analyzed in this study.

When the SFE values were compared among the three different substrata, resin cement was the most hydrophobic, while enamel was the most hydrophilic. Although it was reported that porcelain was highly hydrophilic, the porcelain used in this study, Vitablocs Mark II, was relatively hydrophobic, with an SFE value similar to that of resin cement. Since Vitablocs Mark II is a porcelain material used inCAD/ CAM inlay system, its composition may be different from regular porcelain to enable easy milling with a diamond disk or point. The surface of the three different substrata had wide variations in SFE before saliva-coating (range from 38.4 to 66.7 $\left.\mathrm{mJ} / \mathrm{m}^{2}\right)$ but a saliva-coating made the SFE values almost uniform $\left(53.0-54.6 \mathrm{~mJ} / \mathrm{m}^{2}\right)$. These findings were in agreement with those reported by Van Dijk et al. ${ }^{11}$

When measuring the SFE values of four bacterial stains, S. mitis NCTC12261, $S$. oralis ATCC9811 and S. sanguis ATCC10556 $\left(\mathrm{SFE}=44.2,47.2\right.$ and $49.8 \mathrm{~mJ} / \mathrm{m}^{2}$, respectively) had relatively hydrophobic surfaces, while the surface of S. sobrinus OMZ176 $\left(\mathrm{SFE}=63.4 \mathrm{~mJ} / \mathrm{m}^{2}\right)$ was hydrophilic. S. sobrinus OMZ176 showed the least adhesion to all materials among the four strains, with or without a saliva-coat. Bussher et $a l^{12)}$ demonstrated that low SFE bacteria adhered preferentially to low SFE solid substrata, while high SFE bacteria did so to high SFE substrata, when they measured the SFE of oral streptococci adhered in vivo to the substrata with various SFEs. In our study, S. sobrinus OMZ176 cells with a very hydrophilic surface, showed high affinity to enamel which had the most hydrophilic surface among three substrata. These results were in good agreement with Busscher et al. Therefore, its low 
adhesion may be due to S. sobrinus OMZ176 having the highest hydrophilic surface property. Although it is fortunate that S. sobrinus, one of the major cariogenic bacteria, hardly adheres to restorative materials and enamel in the initial stage of bacterial accumulation, it probably adheres on the biofilm formed by initial adhered bacteria in the later stage.

With respect to bacterial adhesion to various materials, the order for number of adhered cells of all oral streptococci, except S. sanguis ATCC10556, was enamel $>$ porcelain $>$ resin cement in the case of specimens without a saliva-coat. The saliva-coating dramatically decreased the number of adhered streptococci in our study. Satou et $a l .^{13)}$ also reported a reduction in adhered bacteria with a saliva-coat and they suggested that the decreased hydrophobicity of restorative materials due to a saliva-coat may be at least in part responsible for the observed decrease in bacteria. It is thought that the reduction in bacterial adhesion to porcelain and resin cement was related to the decreasing hydrophobicity of these substrata. On the other hand, the SFE values of enamel reduced after a saliva-coat, indicating it became more hydrophobic, although the number of bacteria adhering to enamel decreased with a saliva-coat. Therefore, it is impossible to explain the reduction in bacterial adhesion to enamel after a saliva-coat by the change in the SFE value alone, and other interactions may be associated with the adhesion to enamel.

When comparing the tendency of adhered cells to reduce with a saliva-coat among the bacterial strains tested, the adhesion of S. sanguis ATCC10556 to enamel was not strongly reduced by a saliva-coat, although treatment with a saliva-coat dramatically reduced its adhesion to porcelain and resin cement. Our results may indicate that other interaction is associated with the adhesion of $S$. sanguis to enamel. Morris et al. ${ }^{14)}$ examined the adhesion of $S$. sanguis to saliva-coated hydroxyapatite and suggested that the neuraminidase-sensitive receptor of $S$. sanguis was associated with the adhesion to saliva-coated hydroxyapatite.

In this study, a thermodynamic approach was also used to evaluate the bacterial adhesion to the three materials. The change in interfacial free energy $(\Delta G a d h)$ has been applied to evaluate the bacterial adhesion to solids ${ }^{15,16)}$. Gerson et al. ${ }^{17)}$ reported that the adhesion of bacteria to hydrophobic surfaces was affected by $\Delta G a d h$. A negative $\Delta$ Gadh indicates that adhering bacteria are more stable than floating bacteria from the standpoint of thermodynamic theor ${ }^{18)}$, so that a negative $\Delta G a d h$ is favorable for bacterial adhesion, while a positive $\Delta$ Gadh is unfavorable. When the relationship between $\Delta G a d h$ and the number of adhered cells to all materials, excluding enamel without a saliva-coat, was analyzed, the adhered cells tended to reduce in number with increasing $\Delta G a d h$ values. In other words, bacterial adhesion to porcelain and resin cement could be explained by a thermodynamic approach, while bacterial adhesion to enamel was not related to $\Delta$ Gadh. These results indicate the possibility of a different mechanism in the initial adhered strains of streptococci between enamel and dental restorative materials.

In this study, we examined the hydrophobicity of substrata and evaluated the bacterial adhesion to them. However, it has been reported that bacterial adhesion to 
solid surfaces is attributed to electrostatic forces and also to hydrophobic interactions ${ }^{13)}$. Furthermore, An et al. ${ }^{19)}$ stated that the process of bacterial adhesion was a complicated process affected by many factors, including the characteristics of the bacteria, the target material surface and environmental factors.

Although it may be difficult to understand the adhesion mechanisms of oral streptococci to dental materials and enamel, further research will be done based on the findings obtained in this study.

\section{ACKNOWLEDGMENTS}

This study was supported in part by a Grand-in-Aid for Scientific Research (B) (2) (No.11470405) from the Ministry of Education, Science, Sports and Culture of Japan.

\section{REFERENCES}

1) Lundin, S. A. and Emilson, C. G.: Microflora in plaque from approximal posterior composite resin restorations, Quintessence Int $20: 413-416,1989$.

2) Fitzgerald, R. J., Adams, B. D. and Davis, M. E.: A microbiological study of recurrent dental caries, Caries Res $28:$ 409-415, 1994.

3) Gonzalez-Cabezas, C., Li, Y., Gregory, R. L. and Stookey, G. K.: Distribution of three cariogenic bacteria in secondary carious lesions around amalgam restorations, Caries Res 33 : 357-365, 1999.

4) Nyvad, B. and Kilian, M.: Microbiology of the early colonization of human enamel and root surface in vivo, Scand J Dent Res $95: 369-380,1987$.

5) Nyvad, B. and Kilian, M.: Comparison of the initial streptococcal microflora on dental enamel in caries-active and in caries-inactive individuals, Caries Res $24: 267-272,1990$.

6) Hamada, S., Slade, H. D. and Hutton, D. S.: Adherence of streptococcus mutans to smooth surface, In: Bacterial Adherence, (ed. By Beachy, E. H.), pp.105-135, Chapman and Hall, New York, 1980.

7) Shahal, Y., Steinberg, D., Hirschfeld, Z., Bronshteyn, M. and Kopolovic, K.: In vitro bacterial adherence onto pellicle-coated aesthetic restorative materials, $J$ Oral Rehabil $25: 52-58,1998$.

8) Fowkes, F. M.: Attractive force at interface, Ind Eng Chem $12: 40-52,1964$.

9) Busscher, H. J., Weekamp, A. H., Van Der Mei, H. C., Van Pelt, A. W. J., DE Jong, H. P. and Arends, J.: Measurement of the surface free energy of bacterial cell surface and its relevance for adhesion, Appl Environ Microbiol 48 : 980-983, 1984.

10) Satou, J., Fukunaga, A., Satou, N., Shintani, H. and Okuda, K.: Streptococcal adherence on various restorative materials. J Dent Res $67: 588-591,1988$.

11) Van Dijk, J., Herkstroter, F., Busscher, H.J., Weerkamp, A., Jansen, H. and Arends, J.: Surface-free energy and bacterial adhesion, An in vivo study in beagle dogs, $J$ Clin Periodontol 14 : 300-304, 1987.

12) Busscher, H.J. and Weekamp, A. H.: Specific and non-specific interactions in bacterial adhesion to solid substrata, FEMS Microbiology Review 46 : 165-173, 1987.

13) Satou, J., Fukunaga, A., Mirikawa, A., Matsumae, I., Satou, N. and Shintani, H.: Streptococcal adherence to uncoated and saliva coated restorations, J Oral Rehabil 18: 421-429, 1991.

14) Morris, E. J. and McBride, B.C.: Adherence of Streptococcus saliva-coated hydroxyapatite: evidence for two binding sites, Infect \& Immunol 43:656-663, 1984.

15) Weekamp, A. H., Quriynen, M., Marechal, M., Van Der Mei, H. C., Streenberghe, D. V. and Busscher, H. J.: The role of structure free energy in the early in vivo formation of 
dental plaque on human enamel and polymeric substrata, Microbial Ecology In Health And Disease 2 : 11-18, 1989.

16) Uyen, M., Busscher, H. J., Weekamp, A. H. and Arends, J.: Surface free energies of oral streptococci and their adhesion to solids, FEMS Microbiology Letters 30 : 103-106, 1985.

17) Gerson, D. F. and Scheer, D.: Cell surface energy, contact angles and phase partition. III. Adhesion of bacterial cells to hydrophobic surface, Biochimica et Biophysia Acta $602: 506-510,1980$.

18) Quiryen, M.: The clinical meaning of the surface roughness and surface free energy of intra-oral hard substrata on the microbiology of the supra- and subgingival plaque: results of in vitro and in vivo experiments, J Dent 22 Suppl 1: S13-16, 1994.

19) An, Y. H. and Friedman, R. J.: Concise review of mechanisms of bacterial adhesion to biomaterial surfaces, J Biomed Mater Res $43: 338-348,1998$. 